\title{
Simultaneous Determination of Deoxynivalenol, Deoxynivalenol-3-Glucoside and Nivalenol in Wheat Grains by HPLC-PDA with Immunoaffinity Column Cleanup
}

\author{
Felipe Trombete ${ }^{1,2}$ - Aline Barros ${ }^{2} \cdot$ Madalena Vieira $^{2}$ - Tatiana Saldanha ${ }^{3}$. \\ Armando Venâncio ${ }^{2} \cdot$ Marcelo Fraga $^{4}$
}

Received: 8 December 2015 / Accepted: 15 February 2016 / Published online: 23 February 2016

(C) Springer Science+Business Media New York 2016

\begin{abstract}
Deoxynivalenol-3-glucoside (D3G) is a modified mycotoxin formed by the metabolism of plants through the conjugation of deoxynivalenol (DON) with glucose. Toxicology studies of D3G for human and animal health are still under investigation, and the development of practical and reliable methods for its direct determination, especially in cereal matrices, is of great importance. In the present study, a methodology for simultaneous determination of D3G, DON, and nivalenol (NIV) in wheat grains, using immunoaffinity column (IAC) cleanup, separation by C18 column and detection by ultraviolet (UV) absorption, was optimized and inhouse validated. The results demonstrated adequate values of D3G recovery from IAC and spiked samples. Intraday precision, linearity, limit of detection and limit of quantification (LOQ) were also adequate for the determination of these mycotoxins. Range of applicability varied from 47.1 to $1000 \mu \mathrm{g} /$ $\mathrm{kg}$ for D3G and from 31.3 to $1000 \mu \mathrm{g} / \mathrm{kg}$ for DON and NIV, with recovery ranging from $84.7 \pm 7.2 \%$ to $112.3 \pm 8.1 \%$. A high incidence of D3G (41.2 \%, all samples $<$ LOQ) was verified in commercial samples of wheat grains and whole wheatflour $(n=17)$. Also, the presence of D3G occurred
\end{abstract}

Felipe Trombete

felipetrombete@gmail.com

1 Postgraduate Program in Food Science and Technology, Federal Rural University of Rio de Janeiro, Seropédica 23851-970, Brazil

2 Centre of Biological Engineering, University of Minho, Campus de Gualtar, 4710-057 Braga, Portugal

3 Department of Food Technology, Federal Rural University of Rio de Janeiro, Seropédica 23851-970, Brazil

4 Department of Microbiology and Immunology Veterinary, Federal Rural University of Rio de Janeiro, Seropédica 23851-970, Brazil simultaneously with DON in $100 \%$ of the D3G-positive samples. DON levels varied from $<\mathrm{LOQ}$ to $325.8 \mu \mathrm{g} / \mathrm{kg}$, and NIV was detected in only $29.5 \%$ (from $<\mathrm{LOQ}$ to $140.6 \mu \mathrm{g} / \mathrm{kg}$ ). To the best of our knowledge, this is the first method of simultaneous determination of NIV, D3G, and DON by highperformance liquid chromatography with photodiode array detector (HPLC-PDA) reported until now.

Keywords Modified mycotoxin · Trichothecene · D3G · DON $\cdot$ Method validation

\section{Introduction}

Wheat is the most widely cultivated cereal in the world and a fundamental source of nutrients for humans, contributing to about $20 \%$ of the total dietary calories consumed worldwide (Shiferaw et al. 2013). The consumption of whole-wheat grain and its whole derivatives is a source of dietary fiber, vitamins, minerals, and other bioactive components that are associated with the prevention of some chronic disease, such as, cardiovascular disease, obesity, and cancer (Gil et al. 2011; Borneo and León 2012; Walter et al. 2013). On the other hand, wheat grains can also be a source of mycotoxins, which are toxic metabolites produced by fungi, representing a hazard due to the diverse toxic effects on humans and animals (Pitt 1989; EFSA 2012).

The main mycotoxin producers related to wheat are Ascomycete fungus (Fusarium and Microdochium species) that infects wheat crops causing Fusarium head blight, a global disease responsible for significant crop losses of this cereal (Kazan et al. 2012; McMullen et al. 2012). Fusarium head blight is also related to the contamination of wheat grains by some trichothecene mycotoxins, especially deoxynivalenol (DON) (Stępień and Chełkowski 2010; Del Ponte et al. 
2012; Ji et al. 2015). DON is an immunosuppressive toxin that induces intestinal pathologies, increases the susceptibility to enteric infectious diseases, and it can also affect the central nervous system (Bonnet et al. 2012; Pinton and Oswald 2014). DON can be found in plant materials in its free form, but also conjugated with organic compounds, such as a glucose molecule. This conjugated compound is named deoxynivalenol-3-glucoside (D3G) and it is formed by the metabolism of some plants as a mechanism of resistance against DON, which is subsequently stored in the plant matrix (Berthiller et al. 2005; Berthiller et al. 2009a).

D3G has a much higher polarity than DON and consequently, it escapes routine detection methods, but it contributes to the total mycotoxin content, and it was classified as a "masked mycotoxin", according to a terminology proposed by Gareis (1994) or "modified mycotoxin", as recently proposed by Rychlik et al. (2014). Current concern regarding the presence of $\mathrm{D} 3 \mathrm{G}$ in the food plant matrix is due to the possibility that this conjugated mycotoxin can be hydrolyzed by food processes, such as fermentation, or by human metabolism, releasing its precursor, DON (De Angelis et al. 2014; Dall'Erta et al. 2013; Gratz et al. 2013).

New methodologies to determinate D3G in different food matrices have been optimized in recent years. The main methodologies have been based on HPLC coupled to mass spectrometer (HPLC-MS/MS), which has the advantages of minimal sample treatment, with low detection limits, the possibility to generate structural information of the compounds, and good reliability of the results (Berthiller et al. 2007; Köppen et al. 2010). On the other hand, MS equipment is very expensive and it requires specialized analysts. An alternative to the MS method is the indirect determination of DON conjugates using acid hydrolysis, with quantification by the enzymelinked immunosorbent assay (ELISA). In the last 5 years, three indirect determination methods have been published based on the principle that DON-conjugated mycotoxin can be measured by subtracting the free DON from the total DON obtained after hydrolysis (Liu et al. 2005; Zhou et al. 2007; Tran and Smith 2011). The hydrolysis procedure was considered by these authors as a cheaper and simpler alternative to determine total DON-conjugated mycotoxins in cereals, especially because it uses quantification by ELISA kits. However, Malachová et al. (2015) recently published a critical evaluation of these indirect methods for total DON-conjugated determination, raising doubts on their efficacy as, according to these authors, none of them were able to release DON from its conjugated form, and for this reason, they were not recommended for such evaluations.

Analysis of D3G in cereals by HPLC with ultraviolet (UV) detection was published by Geng et al. (2014), who used an hydrophilic interaction liquid chromatography (HILIC) column to separate D3G after its purification by immunoaffinity columns (IAC). The method was compared to another that uses LC-MS/MS and showed similar results, which according to the authors could be used for direct determination of D3G as an alternative to LC-MS/MS but with the disadvantage of quantifying only D3G and no other trichothecene mycotoxins, such as DON. Moretti et al. (2014) used a method for DON analysis in cereal products, which uses IAC purification and UV detection, to determine both DON and D3G in wheat plant and demonstrated that, due to the cross reactivity of the IAC, it was possible to obtain good values of recovery for both mycotoxins.

In the present study, a method for simultaneous determination of DON, D3G, and also nivalenol (NIV), using immunoaffinity column cleanup and detection by HPLC with a photodiode array (PDA), was optimized and in-house validated. In a second phase, the method was applied to a limited survey on the presence of these mycotoxins in whole-wheat grain products.

\section{Material and Methods}

\section{Reagents and Standards}

NIV (1 mg), D3G (50 $\mu \mathrm{g} / \mathrm{mL}$ in acetonitrile), and DON (1 mg) standards were purchased from Sigma-Aldrich (St. Louis, USA). Standard working solutions $(3 \mu \mathrm{g} / \mathrm{mL})$ were prepared by dilution in HPLC-grade acetonitrile (Chem-Lab Nv Zedelgem, Belgium). Methanol was purchased from Fisher Scientific (Loughborough, UK). Ultrapure water used was obtained by a Milli-Q ${ }^{\circledR}$ purification system (Billerica, USA). Qualitative filter papers were purchased from Filtros Anoia (Barcelona, Spain), and $0.45-\mu \mathrm{m}$ polypropylene membranes were acquired from Whatman (Puradisc 25PP, $25 \mathrm{~mm}$, Buckinghamshire, UK). DON-NIV ${ }^{\mathrm{TM}}$ WB immunoaffinity columns were purchased from Vicam (Watertown, USA).

\section{Sample Extraction and Purification}

The extraction of mycotoxins for validation analysis was performed according to the recommendations of the IAC manufacturer, with minor adaptations, as follows. Whole-wheat grains were ground in a domestic grinder (KRUPS 9000, Solingen, Germany), and $5 \mathrm{~g}$ was transferred to a $50-\mathrm{mL}$ Falcon $^{\text {TM }}$ tube. Then, $20 \mathrm{~mL}$ of water was added and homogenized for $60 \mathrm{~min}$ with a magnetic stirring bar. After this, the tubes were centrifuged for $10 \mathrm{~min}$ at $1000 \mathrm{~g}$ (Sigma $4 \mathrm{~K} 15$ centrifuge, St. Louis, USA). The whole supernatant extract was filtered through a filter paper using vacuum, and $10 \mathrm{~mL}$ of this was vortexed with $40 \mathrm{~mL}$ of phosphate-buffered saline solution (PBS). This solution was then filtered through a $0.45-\mu \mathrm{m}$ membrane and exactly $12 \mathrm{~mL}$ of the filtrate was passed by gravity into the IAC. The column was washed with $10 \mathrm{~mL}$ of PBS followed by $10 \mathrm{~mL}$ of water. The mycotoxins 
were eluted by passing $0.5 \mathrm{~mL}$ of methanol and $1.5 \mathrm{~mL}$ of acetonitrile into the IAC, both by gravity. The extracts were collected in a 4-mL amber vial and dried using a heat block at $45^{\circ} \mathrm{C}$, under a stream of $\mathrm{N}_{2}$. Two-hundred microliter of the mobile phase (10\% acetonitrile in water) was added to the tube, vortexed for $1 \mathrm{~min}$, and then transferred to an HPLC vial insert $(0.25-\mathrm{mL}$ capacity) for the chromatography analysis.

\section{HPLC-PDA analysis}

The HPLC analyses were carried out by a Shimadzu Liquid Chromatography system (Kyoto, Japan) consisting of a SPDM20A PDA detector (scanning from 190 to $400 \mathrm{~nm}$ ), a SIL$30 \mathrm{AC}$ autosampler (volume of injection equal to $50 \mu \mathrm{L}$ ), a DGU-20A5R degassing unit, a LC-30 AD pump, with mobile phase composed of $10 \%$ acetonitrile in water, in the isocratic mode at $1 \mathrm{~mL} / \mathrm{min}$ (pump pressure equal to $9.6 \mathrm{Mpa}$ ), and a CTO-20 AC column oven (at $40{ }^{\circ} \mathrm{C}$ ). The chromatographic separation was performed with a C18 $250 \times 4.6 \mathrm{~mm}$ Teknokroma LC2 column (Barcelona, Spain), particle size of $5 \mu \mathrm{m}$. Run time corresponded to $13 \mathrm{~min}$ for both the samples and standards.

\section{Validation Method}

\section{Recovery of Mycotoxins from IAC}

The first step of the validation method was the evaluation of the capacity of IAC to retain D3G, as the manufacturer only mentioned the values for DON and NIV (described as higher than $99 \%$ for both mycotoxins when $0.125 \mu \mathrm{g}$ of each mycotoxin diluted in PBS was passed into the IAC). Therefore, an aliquot of each mycotoxin (NIV, D3G, and DON) was put together in a glass flask, dried at $45^{\circ} \mathrm{C}$ using a stream of $\mathrm{N}_{2}$, diluted in $12 \mathrm{~mL}$ of PBS by vortexing, and then passed into the IAC. The column was washed with PBS and water; the mycotoxins were eluted using methanol and acetonitrile, dried, and then resuspended in $200 \mu \mathrm{L}$ of the mobile phase, as previously described. Two different mycotoxin levels were investigated, 0.06 and $0.6 \mu \mathrm{g}$, which corresponded to a contamination in a wheat grain sample equivalent to 100 and $1000 \mu \mathrm{g} / \mathrm{kg}$, respectively. For instance, if a sample contained $1000 \mu \mathrm{g} / \mathrm{kg}$ of each of the evaluated mycotoxins, a total amount passed into the IAC would correspond to $1.8 \mu \mathrm{g}$, and in this way, $90 \%$ of the total column capacity $(2 \mu \mathrm{g})$ was used. We chose not to use $100 \%$ of the IAC capacity due to the possibility that it could retain other mycotoxins of minor occurrence, such as 3-acetyldeoxynivalenol (3ADON) and 15-acetyldeoxynivalenol (15ADON) (neither of which were evaluated in this study).
Spiking Experiments

The recovery studies were conducted by spiking a wheat grain sample, in which the presence of the mycotoxins had not been detected. Five-gram samples were spiked with NIV, D3G, and DON together, in triplicates, at concentrations equivalent to 100,500 , and $1000 \mu \mathrm{g} / \mathrm{kg}$. The spiked samples were than kept at room temperature for $12 \mathrm{~h}$ until performing the extraction procedures, in order to evaporate the solvent.

\section{Analytical Curves and Limits of Detection and Quantification}

Analytical curves of NIV, D3G, and DON were built up using seven points of concentration of the three mycotoxins together diluted in the mobile phase $(10 \%$ acetonitrile in water), varying from 0.0625 to $3.0 \mu \mathrm{g} / \mathrm{mL}$. Limits of detection and quantification (LOD and LOQ) were determined at a signal-to-noise ratio $(\mathrm{S} / \mathrm{N})$ of 3 and 10 , respectively, of the chromatograms from the analyses of spiked samples.

\section{Chromatography Optimization}

In order to find the best selectivity to determine the three mycotoxins in the same chromatography run, especially to obtain the separation of $\mathrm{D} 3 \mathrm{G}$ from DON, different conditions of the mobile phase, column, and oven temperature were evaluated. To carry this out, an extract of a spiked sample was injected into three different columns and conditions: a Kinetex UHPLC HILIC $100 \times 4.6 \mathrm{~mm}$ (particle size $2.6 \mu \mathrm{m}$ ) column (Phenomenex, Torrance, USA), with mobile phase composed of $\mathrm{ACN}$ :water or $\mathrm{MeOH}$ :water from 85:15 $(v / v)$ until 95:5 $(v / v)$, with a flow from 0.2 to $0.6 \mathrm{~mL} / \mathrm{min}$; a Kinetex UHPLC C18 $100 \times 3.0 \mathrm{~mm}$ (particle size $2.6 \mu \mathrm{m}$ ) column (Phenomenex, Torrance, USA), with mobile phase composed of $\mathrm{ACN}$ :water or $\mathrm{MeOH}$ :water from 5:95 $(v / v)$ until 15:85 $(v / v)$, with a flow from 0.2 to $0.6 \mathrm{~mL} / \mathrm{min}$; and a Teknokroma LC2 HPLC C18 $250 \times 4.6 \mathrm{~mm}$ (particle size $5 \mu \mathrm{m}$ ) column (Barcelona, Spain), with mobile phase composed of ACN:water or $\mathrm{MeOH}$ :water from 5:95 $(v / v)$ until 15:85 $(v / v)$, with a flow from 0.6 to $1.5 \mathrm{~mL} / \mathrm{min}$. The influence of the oven temperature was evaluated for the three columns, from 20 until $45{ }^{\circ} \mathrm{C}$. Due to the different values described in the literature, wavelengths from 218 to $222 \mathrm{~nm}$ were evaluated in order to obtain the greatest peak area of each mycotoxin evaluated.

\section{Survey on Mycotoxins in Whole-Wheat Products}

The optimized and in-house validated method was used to carry out a limited survey for the presence of NIV, D3G, and 
DON in naturally contaminated samples of whole-wheat grains $(n=13)$ and whole-wheat flour (100\% ground wheat grains, $n=4)$. Samples were acquired in 2015 from different food stores in the city of Braga, Portugal. Packets containing 500 to $1000 \mathrm{~g}$ were collected, transported to the laboratory, and kept at room temperature until analysis. For both wheat grains and wheat flour samples, $50 \mathrm{~g}$ were transferred to a $500-\mathrm{mL}$ Erlenmeyer flask and $200 \mathrm{~mL}$ of water was added and homogenized for $60 \mathrm{~min}$ with a magnetic stirring bar. From this extract, $25 \mathrm{~mL}$ was transferred to a $50-\mathrm{mL}$ Falcon ${ }^{\mathrm{TM}}$ tube and then the purification was carried out as described previously, in the "Sample Extraction and Purification" item. Mycotoxin determinations were carried out with the limitation of only one replicate.

\section{Results and Discussion}

\section{Method Optimization and Validation}

In order to obtain the best separation of NIV, D3G, and DON, three LC columns were evaluated: a UHPLC HILIC column, a UHPLC C18 column, and an HPLC C18 column. In the HILIC column, no proportion of $\mathrm{MeOH}$ :water was able to obtain a separation of D3G from DON. The best condition was the use of $\mathrm{ACN}$ :water $(93: 7, v / v)$, at $0.6 \mathrm{~mL} / \mathrm{min}$, volume of injection equal to $20 \mu \mathrm{L}$, oven temperature at $25^{\circ} \mathrm{C}$, and run time equal to $7 \mathrm{~min}$. However, under these conditions, DON and NIV have poor interactions with the column and could not be detected with reliability. In the UHPLC C18
Fig. 1 Chromatogram obtained by HPLC-PDA from wheat grain samples. a Blank sample. b Spiked sample at $500 \mu \mathrm{g} / \mathrm{kg}$ of each mycotoxin. c Natural occurrence of the three mycotoxins in a commercial sample (NIV and D3G under the LOQ; DON corresponded to $196 \mu \mathrm{g} / \mathrm{kg}$ ). Retention time corresponded to 5.7, 8.7, and 10.1 min for NIV, D3G, and DON, respectively

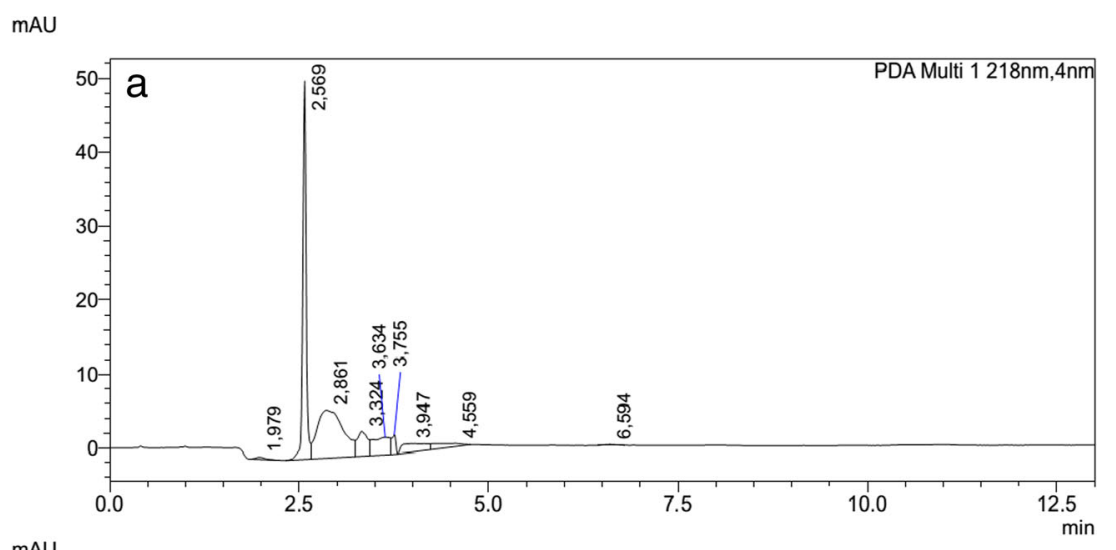

mAU

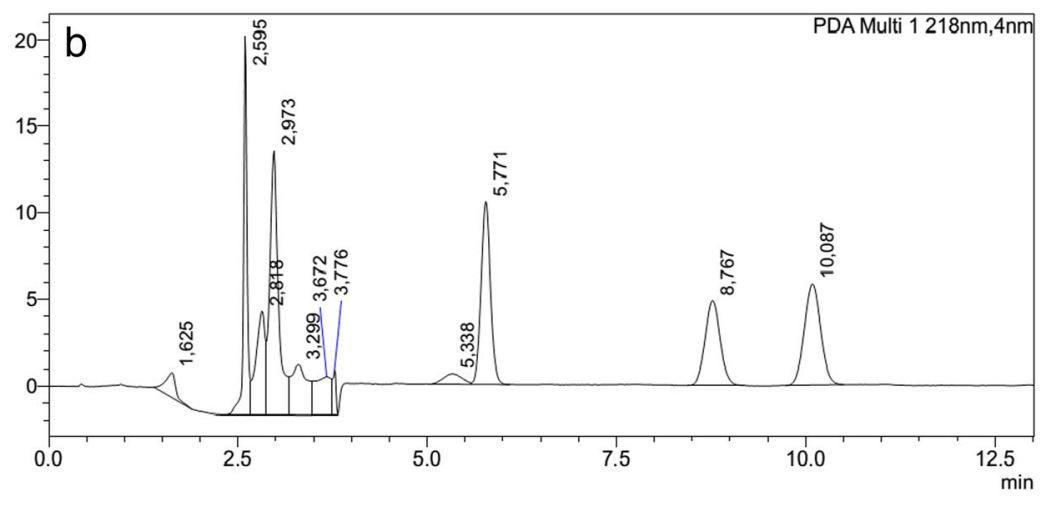

mAU

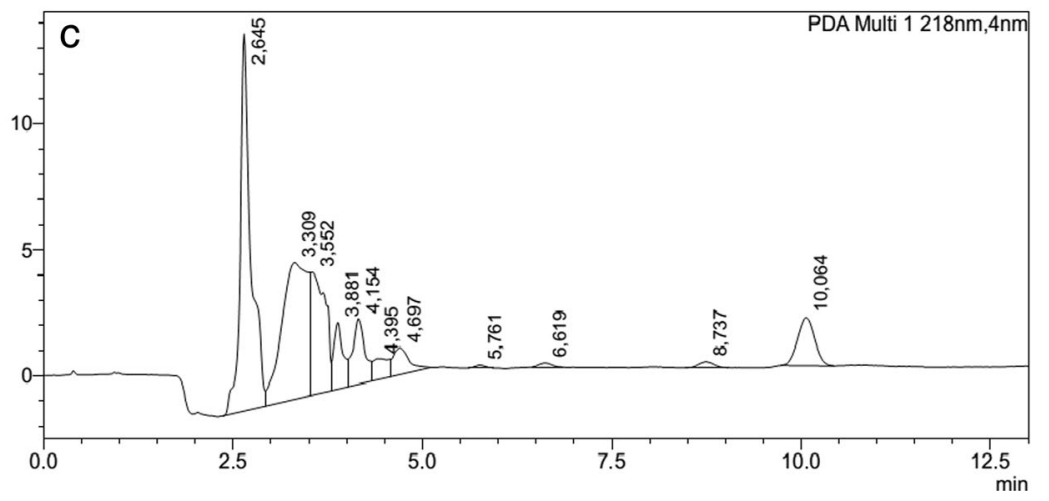


column, the three mycotoxins were separated using ACN:water $(10: 90, v / v)$ at $0.6 \mathrm{~mL} / \mathrm{min}$, volume of injection of $20 \mu \mathrm{L}$ and oven temperature at $25^{\circ} \mathrm{C}$. However, the interference of the matrix did not allow clear identification of the mycotoxins. The best condition of separation of the mycotoxins was achieved by using the traditional $\mathrm{C} 18$ column with mobile phase composed of ACN:water $(10: 90, v / v)$, at $1 \mathrm{~mL} /$ min, volume of injection equal to $50 \mu \mathrm{L}$, and column oven at $40^{\circ} \mathrm{C}$. Under these conditions, retention time corresponded to 5.7, 8.7, and $10.1 \mathrm{~min}$ for NIV, D3G, and DON, respectively (Fig. 1).

The use of IAC for the cleanup of extracts containing mycotoxins has the advantaged of improving the selectivity of the method by removing interfering compounds and concentrating the mycotoxin, which consequently lowers the LOD and LOQ. Its cross-reactivity with the modified forms of mycotoxins depends on the immobilized antibody. To determine the conjugated mycotoxins without a hydrolysis step, such as D3G, an antibody with high cross-reactivity is preferred in order to obtain good recovery rates (Goryacheva and De Saeger 2012). To the best of our knowledge, the DON$\mathrm{NIV}^{\mathrm{TM}}$ IAC used in this study has never been used to evaluate the percentage recovery of D3G until now. The results obtained are presented in Table 1 and demonstrated that it was possible to obtain good values of recovery of the three mycotoxins evaluated, which varied from 90.8 to $115.5 \%$. Therefore, this IAC can be considered adequate for purification and concentration of NIV, D3G, and DON, with further quantification by HPLC-PDA or even MS/MS.

In order to evaluate the percentage recovery and the intraday precision (in terms of \% RSD) of the optimized method, NIV, D3G, and DON were spiked in wheat grain samples and then submitted to the extraction procedures. The results presented in Table 2 demonstrated adequate values, varying from $84.7 \pm 7.2$ to $112.3 \pm 8.1 \%$. The LOD corresponded to $9.4 \mu \mathrm{g} /$ $\mathrm{kg}$ for NIV and DON and $14.1 \mu \mathrm{g} / \mathrm{kg}$ for D3G, while the LOQ

Table 1 Percent recoveries of NIV, D3G, and DON from the IAC

\begin{tabular}{|c|c|c|}
\hline $\begin{array}{l}\text { Amount of mycotoxin } \\
\text { passed into IAC }\end{array}$ & $\begin{array}{l}\text { Equivalent in the } \\
\text { method }\end{array}$ & Recovery (RSD \%) \\
\hline $0.06 \mu \mathrm{g}$ of each & $\begin{array}{l}100 \mu \mathrm{g} / \mathrm{kg} \text { of each } \\
\text { mycotoxin }\end{array}$ & $\begin{array}{l}\text { NIV } 115.5 \%(8.2) \\
\text { D3G } 99.3 \%(5.5) \\
\text { DON } 97.5 \%(11.0)\end{array}$ \\
\hline$\sum=0.18 \mu \mathrm{g}$ & $\begin{array}{l}300 \mu \mathrm{g} / \mathrm{kg} \text { of total } \\
\text { mycotoxins }\end{array}$ & $\begin{array}{l}\text { Total recovered } \\
104.1 \%(7.2)\end{array}$ \\
\hline $0.6 \mu \mathrm{g}$ of each & $\begin{array}{l}1000 \mu \mathrm{g} / \mathrm{kg} \text { of each } \\
\text { mycotoxin }\end{array}$ & $\begin{array}{l}\text { NIV } 90.8 \%(14.3) \\
\text { D3G } 93.0 \%(7.7) \\
\text { DON } 94.5 \%(4.5)\end{array}$ \\
\hline$\sum=1.8 \mu \mathrm{g}$ & $\begin{array}{l}3000 \mu \mathrm{g} / \mathrm{kg} \text { of total } \\
\text { mycotoxins }\end{array}$ & $\begin{array}{r}\text { Total recovered } \\
92.8 \%(8.5)\end{array}$ \\
\hline
\end{tabular}

Table 2 Mean recoveries and RSD of NIV, D3G, and DON spiked in wheat grains, at different spiking levels

\begin{tabular}{llcl}
\hline Mycotoxin & Spike levels $(\mu \mathrm{g} / \mathrm{kg})$ & Mean recovery $(\%) \pm \mathrm{SD}$ & $\mathrm{RSD}$ \\
\hline NIV & 100 & $109.4 \pm 3.6$ & $3.6 \%$ \\
& 500 & $88.0 \pm 11.7$ & $13.3 \%$ \\
& 1000 & $100.3 \pm 10.7$ & $10.7 \%$ \\
D3G & 100 & $95.2 \pm 17.1$ & $18.0 \%$ \\
& 500 & $94.7 \pm 14.0$ & $14.8 \%$ \\
& 1000 & $84.7 \pm 7.2$ & $8.5 \%$ \\
DON & 100 & $112.3 \pm 8.1$ & $7.2 \%$ \\
& 500 & $99.7 \pm 9.5$ & $9.6 \%$ \\
& 1000 & $94.1 \pm 5.5$ & $5.8 \%$ \\
\hline
\end{tabular}

corresponded to $31.3 \mu \mathrm{g} / \mathrm{kg}$ for NIV and DON and $47.1 \mu \mathrm{g} / \mathrm{kg}$ for D3G.

DON is the only one of these mycotoxins that is regulated by regulatory agencies. The U.S. Food and Drug Administration sets maximum limits for cereal products intended for human consumption equal to $1000 \mu \mathrm{g} / \mathrm{kg}$ (FDA 2011), while in the European Union, its levels vary from $200 \mu \mathrm{g} / \mathrm{kg}$ for foods for infants to $1750 \mu \mathrm{g} / \mathrm{kg}$ for unprocessed cereal (EC 2006). Based on this, the LOQ found in this work could be considered adequate for the evaluation of this mycotoxin in wheat grain samples. Different values of LOQ to determine $\mathrm{D} 3 \mathrm{G}$ in cereal samples, using LC-MS/MS, have been reported in the literature, for example, $5 \mu \mathrm{g} / \mathrm{kg}$ in the method used by Škrbić et al. (2011) and $100 \mu \mathrm{g} / \mathrm{kg}$, as described by Vendl et al. (2010). Geng et al. (2014) who used an HPLC-UV method reported a lower LOQ than that found in the present study, corresponding to $25 \mu \mathrm{g} / \mathrm{kg}$.

All the analytical curves showed $R^{2}$ higher than 0.999 in the range $0.0625-3.0 \mu \mathrm{g} / \mathrm{mL}$ and the greatest peak area for NIV, D3G, and DON was obtained using absorbance at $218 \mathrm{~nm}$, as demonstrated in Fig. 2.

\section{Occurrence of Mycotoxins in Whole-Wheat Products}

Based on the 17 samples evaluated for the presence of NIV, D3G, and DON, $58.8 \%$ were positive for at least one mycotoxin. DON had the highest prevalence (58.8 \%), followed by D3G (41.2\%) and NIV (29.5\%). Simultaneous occurrence of D3G and DON was observed, because $100 \%$ of the D3Gpositive samples also had detectable levels of DON. No samples of DON exceed the European Commission regulation limits (EC 2006), which are $1250 \mu \mathrm{g} / \mathrm{kg}$ for wheat grains and $750 \mu \mathrm{g} / \mathrm{kg}$ for wheat flour. For NIV, there are no legal limits for its presence in food; however, due to its immunotoxicity and hematotoxicity, the European Food Safety Authority established a tolerable daily intake (TDI) of $1.2 \mu \mathrm{g} / \mathrm{kg}$ b.w. per day (EFSA 2013). Also, no legal maximum 
Fig. 2 Effect of wavelengths $(\mathrm{nm})$ on the peak area $(\%)$ of DON, D3G, and NIV

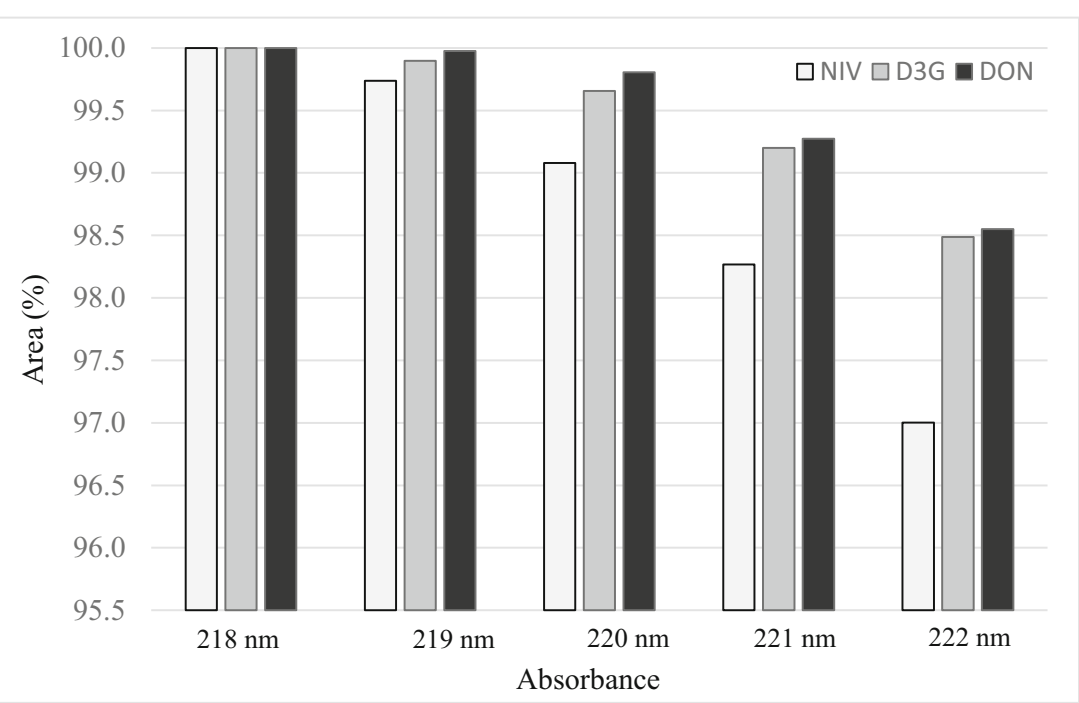

levels have been set for the presence of D3G until now. However, even supposing a total conversion of D3G into DON, not one sample would have reach the maximum allowed levels for DON. These results are presented in Table 3.

Other studies have also demonstrated that D3G can be found in other cereal matrixes at different levels. Vendl et al. (2010) investigated its presence by LC-MS/MS in 25 samples of cereal-based food and found $8 \%$ of positivity $(\mathrm{LOQ}=100 \mu \mathrm{g} / \mathrm{kg}$ ). Škrbić et al. (2011) reported a higher percentage of contamination (13\%), possible due to the lower LOQ of the LC-MS/MS method used $(5 \mu \mathrm{g} / \mathrm{kg})$. These authors evaluated 54 wheat grain samples and reported concentrations from 17 to $83 \mu \mathrm{g} / \mathrm{kg}$. De Boevre et al. (2012) also used a LC-MS/MS method and reported higher levels of D3G in fiber-enriched bread products, varying from 10 to $425 \mu \mathrm{g} / \mathrm{kg}$, and $48 \%$ of the samples were positive.

The highest levels of D3G occurring in a cereal product, reported until now, corresponded to $1070 \mu \mathrm{g} / \mathrm{kg}$ in wheat grains (Berthiller et al. 2009b) and to $1100 \mu \mathrm{g} / \mathrm{kg}$ in maize grain samples (De Boevre et al. 2014). The levels of D3G can be even higher than DON, as reported in a breakfast cereal by Malachova et al. (2011) and in beer samples by Varga et al. (2013). The presence of this modified form of DON in commodities contributes to the exposure of consumers to DON, making it of great importance to the screening of D3G in cereal products, as well as the evaluation of its contribution to DON intake in risk assessment studies.

\section{Conclusions}

The method optimized and in-house validated in this work, by using IAC purification and HPLC-PDA determination, is adequate to determine the conjugated mycotoxin $\mathrm{D} 3 \mathrm{G}$ together with DON and NIV in wheat grain samples. Adequate values of recovery, intraday precision, linearity, LOD, and LOQ were reached. To the best of our knowledge, this is the first method of simultaneous determination of these mycotoxins by HPLCPDA reported until now. By using this method, a high incidence of D3G (41.2\%) was verified in commercial samples of wheat grains and whole wheat flour $(n=17)$ at trace levels $(<\mathrm{LOQ})$. Also, the presence of D3G occurred simultaneously with DON in $100 \%$ of the D3G-positive samples. Suggestions for future research include the validation of these methodologies for other cereal matrixes and the realization of surveys on the simultaneous occurrence of DON and D3G to be used in exposure studies. Possible retention of $3 \mathrm{ADON}$ and $15 \mathrm{ADON}$ by the IAC used in this study should also be
Table 3 Natural occurrence of NIV, D3G, and DON in wholewheat products marketed in Braga, Portugal

\begin{tabular}{llll}
\hline Mycotoxin & \multicolumn{2}{l}{$\%$ of positive samples (and range, in $\mu \mathrm{g} / \mathrm{kg})$} & \\
\cline { 2 - 4 } & Wheat grains $(n=13)$ & Whole-wheat flour $(n=4)$ & Total $(n=17)$ \\
\hline NIV & $7.6 \%(<\mathrm{LOQ})$ & $100 \%(<\mathrm{LOQ}-140.6)$ & $29.5 \%(<\mathrm{LOQ}-140.6)$ \\
D3G & $30.8 \%(<\mathrm{LOQ})$ & $75 \%(<\mathrm{LOQ})$ & $41.2 \%(<\mathrm{LOQ})$ \\
DON & $46.1 \%(<\mathrm{LOQ}-297.3)$ & $100 \%(78.9-325.8)$ & $58.8 \%(<\mathrm{LOQ}-325.8)$ \\
\hline
\end{tabular}

LOQs for NIV, D3G, and DON corresponded to $31.3,47.1$, and $31.3 \mu \mathrm{g} / \mathrm{kg}$, respectively 
investigated, in order to include the determination of these mycotoxins in the same methodology.

Acknowledgments Felipe Trombete is grateful for a doctoral fellowship provided by the Brazilian Federal Agency for Support and Evaluation of Graduate Education (CAPES).

\section{Compliance with Ethical Standards}

Funding This study was financially supported by The Brazilian National Council for Scientific and Technological Development (CNPq, grant number 201198/2014-2-SWE).

Conflict of Interest Felipe Trombete has no conflict of interest. Aline Barros has no conflict of interest. Madalena Vieira has no conflict of interest. Tatiana Saldanha has no conflict of interest. Armando Venâncio has no conflict of interest. Marcelo Fraga has no conflict of interest.

Ethical Approval This article does not contain any studies with human participants or animals performed by any of the authors.

Informed Consent Not applicable

\section{References}

Berthiller F, Dall'Asta C, Schuhmacher R et al (2005) Masked mycotoxins: determination of a deoxynivalenol glucoside in artificially and naturally contaminated wheat by liquid chromatography-tandem mass spectrometry. J Agric Food Chem 53:3421-3425

Berthiller F, Sulyok M, Krska R, Schuhmacher R (2007) Chromatographic methods for the simultaneous determination of mycotoxins and their conjugates in cereals. Int J Food Microbiol 119:33-37

Berthiller F, Schuhmacher R, Adam G, Krska R (2009a) Formation, determination and significance of masked and other conjugated mycotoxins. Anal Bioanal Chem 395:1243-1252

Berthiller F, Dall'Asta C, Corradini R et al (2009b) Occurrence of deoxynivalenol and its $3-\beta$-D-glucoside in wheat and maize. Food Addit Contam Part A 26:507-511

Bonnet M, Roux J, Mounien L et al (2012) Advances in deoxynivalenol toxicity mechanisms: the brain as a target. Toxins (Basel) 4: $1120-1138$

Borneo R, León AE (2012) Whole grain cereals: functional components and health benefits. Food Funct 3:110-119

Dall'Erta A, Cirlini M, Dall'Asta M et al (2013) Masked mycotoxins are efficiently hydrolyzed by human colonic microbiota releasing their aglycones. Chem Res Toxicol 26:305-312

De Angelis E, Monaci L, Visconti A (2014) Investigation on the stability of deoxynivalenol and DON-3 glucoside during gastro-duodenal in vitro digestion of a naturally contaminated bread model food. Food Control 43:270-275

De Boevre M, Di Mavungu JD, Landschoot S et al (2012) Natural occurrence of mycotoxins and their masked forms in food and feed products. World Mycotoxin J 5:207-219

De Boevre M, Landschoot S, Audenaert K et al (2014) Occurrence and within field variability of Fusarium mycotoxins and their masked forms in maize crops in Belgium. World Mycotoxin J 7:91-102
Del Ponte EM, Garda-Buffon J, Badiale-Furlong E (2012) Deoxynivalenol and nivalenol in commercial wheat grain related to Fusarium head blight epidemics in southern Brazil. Food Chem 132:1087-1091

EC (2006) Commission Regulation (EC) No 1881/2006 of 19 December 2006 setting maximum levels for certain contaminants in foodstuffs. Off J Eur Union 5-24. http://eur-lex.europa.eu/legal-content/EN/ ALL/?uri=CELEX\%3A32006R1881. Accessed 20 Feb 2016

EFSA (2012) European Food Safety Authority. Contaminants in food and feed mycotoxins. http://www.efsa.europa.eu/en/topics/topic/ mycotoxins Accessed 27 Jan 2016

EFSA (2013) European Food Safety Authority. Scientific opinion on risks for animal and public health related to the presence of nivalenol in food and feed. EFSA J 11:1-119

FDA (2011) Food and Drug Administration. Mycotoxin regulatory guidance. A guide for grain elevators, feed manufacturers, grain processors and exporters. https://www.ngfa.org/wp-content/uploads/ NGFAComplianceGuide-FDARegulatoryGuidanceforMycotoxins 82011.pdf Accessed 27 Jan 2016

Gareis M (1994) Maskierte mykotoxine. Übers Tierernährung 22: 104-113

Geng Z, Yang D, Zhou M et al (2014) Determination of deoxynivalenol3 -glucoside in cereals by hydrophilic interaction chromatography with ultraviolet detection. Food Anal Methods 7:1139-1146

Gil A, Ortega RM, Maldonado J (2011) Wholegrain cereals and bread: a duet of the Mediterranean diet for the prevention of chronic diseases. Public Health Nutr 14:2316-2322

Goryacheva IY, De Saeger S (2012) Immunochemical detection of masked mycotoxins: a short review. World Mycotoxin J 5: 281-287

Gratz SW, Duncan G, Richardson AJ (2013) The human fecal microbiota metabolizes deoxynivalenol and deoxynivalenol-3-glucoside and may be responsible for urinary deepoxy-deoxynivalenol. Appl Environ Microbiol 79:1821-1825

Ji F, Wu J, Zhao $\mathrm{H}$ et al (2015) Relationship of deoxynivalenol content in grain, chaff, and straw with Fusarium head blight severity in wheat varieties with various levels of resistance. Toxins (Basel) 7:728-742

Kazan K, Gardiner DM, Manners JM (2012) On the trail of a cereal killer: recent advances in Fusarium graminearum pathogenomics and host resistance. Mol Plant Pathol 13:399-413

Köppen R, Koch M, Siegel D et al (2010) Determination of mycotoxins in foods: current state of analytical methods and limitations. Appl Microbiol Biotechnol 86:1595-1612

Liu Y, Walker F, Hoeglinger B, Buchenauer H (2005) Solvolysis procedures for the determination of bound residues of the mycotoxin deoxynivalenol in Fusarium species infected grain of two winter wheat cultivars preinfected with barley yellow dwarf virus. J Agric Food Chem 53:6864-6869

Malachova A, Dzuman Z, Veprikova Z et al (2011) Deoxynivalenol, deoxynivalenol-3-glucoside, and enniatins: the major mycotoxins found in cereal-based products on the Czech market. J Agric Food Chem 59:12990-12997

Malachová A, Štočková L, Wakker A et al (2015) Critical evaluation of indirect methods for the determination of deoxynivalenol and its conjugated forms in cereals. Anal Bioanal Chem 407:6009-6020

McMullen M, Bergstrom G, De Wolf E et al (2012) A unified effort to fight an enemy of wheat and barley: Fusarium head blight. Plant Dis 96:1712-1728

Moretti A, Panzarini G, Somma S et al (2014) Systemic growth of $F$. graminearum in wheat plants and related accumulation of deoxynivalenol. Toxins 6:1308-1324

Pinton P, Oswald I (2014) Effect of deoxynivalenol and other type B trichothecenes on the intestine: a review. Toxins (Basel) 6: $1615-1643$ 
Pitt J 1. (1989) Mycotoxin prevention and control in foodgrains. An introduction to mycotoxins. FAO - Food and Agriculture Organization of the United Nations., Bankok http://www.fao.org/docrep/X5036E/ x5036E00.HTM Accessed 27 Jan 2016

Rychlik M, Humpf HU, Marko D et al (2014) Proposal of a comprehensive definition of modified and other forms of mycotoxins including "masked" mycotoxins. Mycotoxin Res 30:197-205

Shiferaw B, Smale M, Braun H-J et al (2013) Crops that feed the world 10. Past successes and future challenges to the role played by wheat in global food security. Food Secur 5:291-317

Škrbić B, Malachova A, Živančev J et al (2011) Fusarium mycotoxins in wheat samples harvested in Serbia: a preliminary survey. Food Control 22:1261-1267

Stępień Ł, Chełkowski J (2010) Fusarium head blight of wheat: pathogenic species and their mycotoxins. World Mycotoxin J 3:107-119
Tran ST, Smith TK (2011) Determination of optimal conditions for hydrolysis of conjugated deoxynivalenol in corn and wheat with trifluoromethanesulfonic acid. Anim Feed Sci Technol 163:84-92

Varga E, Malachova A, Schwartz H et al (2013) Survey of deoxynivalenol and its conjugates deoxynivalenol-3-glucoside and 3-acetyl-deoxynivalenol in 374 beer samples. Food Addit Contam Part A 30:137-146

Vendl O, Crews C, MacDonald S et al (2010) Occurrence of free and conjugated Fusarium mycotoxins in cereal-based food. Food Addit Contam Part A 27:1148-1152

Walter J, Martínez I, Rose DJ (2013) Holobiont nutrition. Gut Microbes 4:340-346

Zhou B, Li Y, Gillespie J et al (2007) Doehlert matrix design for optimization of the determination of bound deoxynivalenol in barley grain with trifluoroacetic acid (TFA). J Agric Food Chem 55:1014110149 